\title{
CARACTERIZAÇÃO DA CONTAMINAÇÃO POR METAIS PESADOS EM ÁREA DE MANGUEZAL, MUNICÍPIO DE SANTOS (SP)
}

\author{
Janaína Mara FORTUNATO \\ Raphael HYPOLITO \\ Claudia Lucia MOURA \\ Silvia Cremonez NASCIMENTO
}

\begin{abstract}
RESUMO
O presente trabalho teve como objetivo caracterizar a contaminação do solo e das águas subterrâneas e superficiais por metais pesados em uma área de manguezal em Santos (SP), utilizada como local de descarte de resíduos das atividades portuárias por mais de 50 anos. Análises químicas do solo e das águas coletados no local de estudo indicaram que as concentrações de íons de metais pesados $(\mathrm{Pb}, \mathrm{Zn}$, $\mathrm{Cu}, \mathrm{Ni}$ ) encontram-se acima dos valores de referência de qualidade da CETESB. O elevado teor de matéria orgânica do manguezal deve ser o principal responsável pela fixação iônica dos metais no solo. Análises químicas do líquido percolado do aterro, coletado em lagoa próxima, também indicaram a presença de $\mathrm{Pb}^{2+}$ em quantidades elevadas. Extrações de metais do solo com água (fase solúvel) e $\mathrm{HNO}_{3}$ (fases solúvel e adsorvida) indicam a lixiviação desses íons sob condições específicas, o que pode intensificar a dispersão desses contaminantes no ambiente.
\end{abstract}

Palavras-chave: metais pesados, manguezal, aterro, Santos.

\section{ABSTRACT}

This study aimed at evaluating the contamination of soil and superficial and ground waters by heavy metals in a mangrove in Santos Municipality (São Paulo State), where waste from port operations has been disposed for over 50 years. Chemical analyses of soil and water samples collected in the study area indicated that the concentrations of heavy metals ions $(\mathrm{Pb}, \mathrm{Zn}, \mathrm{Cu}, \mathrm{Ni})$ are above the reference values of the Companhia Ambiental do Estado de São Paulo - CETESB (São Paulo State Environmental Agency). The high content of organic matter in the mangrove is probably the main cause of ionic fixation of these metals in the soils. Chemical analysis of the percolated liquid from the landfill, collected in a lagoon, also showed high concentration of $\mathrm{Pb}$. Metal extraction from soils with water (soluble phase) and $\mathrm{HNO}_{3}$ (soluble and adsorbed phases) indicates that the lixiviation of these ions occurred under specific conditions, which can increase the dispersion of these contaminants in the environment.

Keywords: heavy metals, mangrove, landfill, Santos.

\section{INTRODUÇÃO}

As cidades litorâneas sempre enfrentaram dificuldades para a destinação adequada dos seus resíduos sólidos domiciliares e industriais, dada a escassez de áreas propícias para a construção de aterros. Diante dessa problemática e para se enquadrar à Política Nacional dos Resíduos Sólidos, as cidades da Baixada Santista vêm fechando as áreas que serviram como lixões e destinando seus resíduos para aterros controlados particulares, até mesmo de outras localidades, como o Município de Mauá na Grande São Paulo.

No entanto, devido à sua localização estratégica - próxima ao Porto de Santos - essa região tem atraído durante muitos anos grandes empreendimentos industriais, portuários e turísticos, levando ao aumento do volume e da variedade de 
resíduos, que, no passado, eram descartados em áreas inadequadas, como os manguezais. Na Baixada Santista, os manguezais ocorrem ao longo de canais naturais, às margens de lagunas e braços de marés das regiões estuarinas (MASSAD 1999); em alguns pontos, encontram-se degradados por terem sido utilizados por muito tempo como áreas de lixões (FIRME 2003).

O manguezal é um sistema ecológico muito frágil e complexo, uma vez que está constantemente sujeito à influência das marés, na transição entre os ambientes terrestres e marinhos (SCHAEFFERNOVELLI 1991).

Estudos sobre a alteração da qualidade dos solos, sedimentos, ar e águas (superficiais e subterrâneas) nesta porção do litoral paulista (CETESB 1998, SIQUEIRA et al. 2004, SILVA 2004, SIMÕES 2007, HORTELLANI et al. 2008, GOMES et al. 2009, GONÇALVES et al. 2012) indicam que o setor industrial constitui uma das principais fontes de poluição, em função das emissões de carga poluente superior à capacidade de assimilação dos sistemas estuarinos de Santos-Cubatão e de São Vicente. Somam-se a essas fontes aquelas associadas à lixiviação de áreas contaminadas, efluentes domésticos e lançamento de sedimentos contaminados dragados dos canais portuários. A maior parte destes estudos corresponde a diagnósticos regionais dos teores de contaminantes nas águas superficiais e sedimentos dos estuários, sua dispersão e distribuição em profundidade e extensão.

As substâncias tóxicas e carcinogênicas normalmente encontradas nessas áreas podem ser de natureza orgânica (benzo(a)pireno, benzeno, tolueno, etilbenzeno, xileno, hexaclorobenzeno, bifenilas policloradas - PCBs, dioxinas, etc.), organometálica (metil mercúrio) e inorgânica $(\mathrm{Hg}, \mathrm{As}, \mathrm{Al}$, $\mathrm{Zn}, \mathrm{Ni}, \mathrm{Co}, \mathrm{Cu}, \mathrm{Fe}, \mathrm{Mn}, \mathrm{Pb}, \mathrm{Cd}, \mathrm{Cr}$, entre outros) e constituem perigo latente à saúde pública.

Estudos envolvendo efeitos adversos e bioacumulação em organismos (peixes, siris, caranguejos, mariscos, ostras, entre outros) (CETESB 2001a, VIRGA 2006, CARMO et al. 2011) integram estes diagnósticos, uma vez que estão diretamente relacionados à saúde da população ribeirinha que deles se alimenta.

Algumas pesquisas abordaram, em escala local, a contaminação por metais pesados e outros compostos em manguezal, próximo ou associado ao complexo industrial de Cubatão (FERRER 2001, HYPOLITO et al. 2005, NASCIMENTO 2007, BERROCAL 2009). Estes trabalhos enfocam o comportamento dos íons contaminantes em relação aos mecanismos de fixação ou mobilida- de no meio, considerando principalmente as características redutoras do mangue, a presença de matéria orgânica, a composição mineralógica e a influência das águas salinas na elevação da força iônica, entre outros fatores. No Município de Santos (SP), entretanto, há poucos estudos geoquímicos com este enfoque.

Este trabalho teve como alvo de estudo uma área de manguezal completamente degradada, situada dentro dos limites do "Porto Organizado" em Santos (SP). Trabalho prévio (DTA ENGENHARIA 2003) realizado nesta área detectou a presença de íons contaminantes, especialmente metais pesados, que se encontram amplamente distribuídos.

A presente contribuição teve como objetivo caracterizar a contaminação por íons de metais pesados chumbo, zinco, cobre e níquel nos solos/ sedimentos, águas subterrâneas e superficiais (Rio Saboó) na área do aterro.

\section{2 ÁREA DE ESTUDO}

A área de estudo, localizada na Zona Portuária do Município de Santos (SP), dista $70 \mathrm{~km}$ de São Paulo (SP) e faz divisa ao norte com o Estuário de Santos (margem direita do Canal de Piaçaguera), a oeste com o terminal da Petrobrás, a leste com o Rio Saboó e a sul com a Av. Engenheiro Augusto Barata (Figura 1).

\subsection{Aspectos fisiográficos}

A área está inserida na unidade morfoescultural Planíce Litorânea Santista (ROSS \& MOROZ 1997) e apresenta terreno plano, altimetria variando de 0 a $20 \mathrm{~m}$ e declividades inferiores a $2 \%$, associado à sedimentação quaternária marinha e fluvial. Corresponde à Planície de Mangue, onde a foz dos rios atinge o oceano em zonas costeiras baixas e planas, sujeita às oscilações dos níveis de maré.

Devido à força branda das marés e baixa velocidade das correntes, há intensa deposição de sedimentos finos e matéria orgânica, permitindo a formação de substrato lamacento, pouco compactado, alagadiço, com pouco oxigênio e cálcio, mas com abundância de nutrientes (SCHAEFFERNOVELLI 1991, IPT 1998, PRADA-GAMERO 2001, FERREIRA 2002). Os solos recebem a denominação geral de solo indiscriminado de mangue ou sedimento de mangue (EMBRAPA 1995). Caracterizam-se, de modo geral, pela ampla variação de $\mathrm{pH}$ e elevada capacidade de troca catiônica (CTC), capacidade de retenção de água, nitrogênio e fósforo extraível (PRADA-GAMERO 2001). A decomposição da serapilheira e a saturação pela 


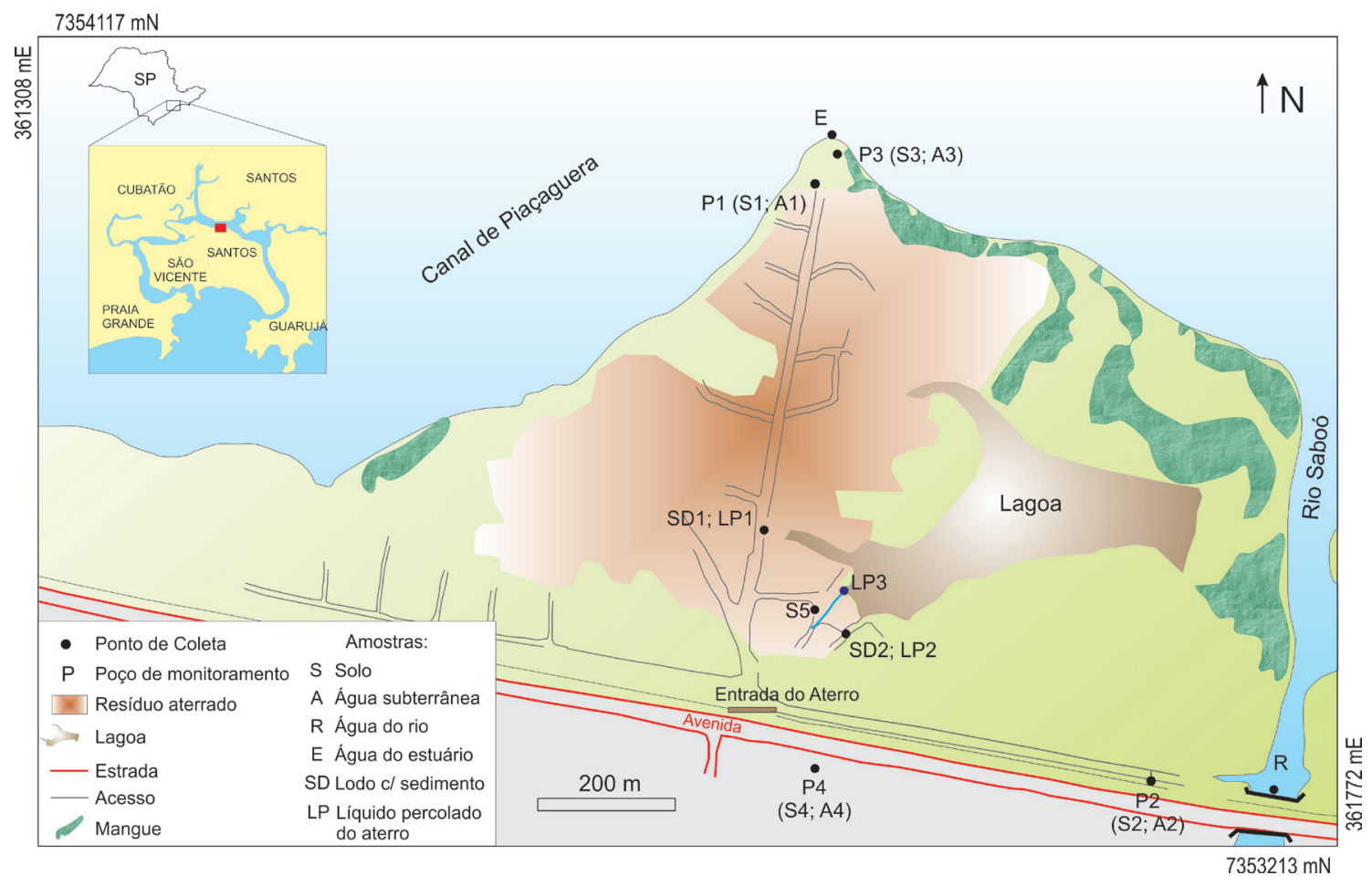

FIGURA 1 - Representação esquemática da área de estudo, indicando a localização dos poços de monitoramento e de amostragem.

água resultam em elevadas concentrações de matéria orgânica, ambiente redutor, com ocorrência de $\mathrm{H}_{2} \mathrm{~S}$ e coloração cinza à preta (FERREIRA 2002).

A Baixada Santista apresenta clima quente e úmido, com temperatura média anual superior a $20^{\circ} \mathrm{C}$ e precipitação anual variando de 2000 a $2500 \mathrm{~mm}$, com chuvas concentradas no verão (janeiro-março). Em função da influência exercida pelo Oceano Atlântico e por massas equatoriais, a umidade relativa do ar é alta ao longo do ano, com média de 80\% (CETESB 1998).

\subsection{Ocupação da área}

A área de estudo correspondia originalmente a um manguezal. Nos últimos 50 anos, o local foi utilizado para a disposição de resíduos sólidos oriundos de atividades relacionadas às operações do Porto de Santos, implicando na remoção de grande parte da cobertura vegetal original.

A partir de 2001, os resíduos, que antes eram descartados a céu aberto, passaram a ser dispostos na forma de aterro controlado. Os resíduos sólidos, constituídos de materiais diversos, como cordas, plásticos, pneus, resíduos de construção civil, etc., foram cobertos por uma camada de aterro de areia argilosa, coloração marrom a cinza, semelhante aos materiais dos manguezais, contendo misturas de brita e entulho. Com o aterro, a topografia do terreno elevou-se cerca de 5 a $10 \mathrm{~m}$.

Em 2006/2007, durante a realização dessa pesquisa, o aterro encontrava-se desativado, com cobertura vegetal secundária e sem nenhum tipo de sistema de coleta de efluentes líquidos. Observou-se que todo efluente líquido produzido na área do aterro estava sendo escoado, por gravidade, até uma lagoa.

\section{MATERIAIS E MÉTODOS}

Os trabalhos foram divididos em duas etapas: (1) trabalhos de campo para amostragem de solos/sedimentos, águas subterrâneas e superficiais e líquido percolado do aterro e (2) análises químicas, granulométricas e mineralógicas das amostras, além de experimentos para extração iônica de metais dos solos.

\subsection{Amostragem}

A área de estudo encontra-se desativada, tendo sido permitida uma única campanha de amostragem, concentrada nos meses de dezembro/2006 e janeiro/2007. Nessa campanha não foi possível avaliar as flutuações de nível d'água e a influência da cunha salina a partir dos poços de monitoramento. 
O material de cobertura sobre os resíduos do aterro é formado em quase sua totalidade por solos misturados com entulhos, o que dificultou a perfuração dos poços de monitoramento e a tradagem ma- nual para coleta de solo e de água. Desta forma, a amostragem foi feita em 4 pontos (P1 a P4), situados nas extremidades da área ou em locais um pouco mais afastados do aterro (Figuras 1 e 2A, Tabela 1).

TABELA 1 - Amostras sólidas e líquidas coletadas na área de estudo.

\begin{tabular}{cccc}
\hline Local & Amostra & Tipo & $\begin{array}{c}\text { Profundidade de } \\
\text { amostragem }(\mathrm{m})\end{array}$ \\
\hline P1 & S1 & Solo/sedimento & $0-0,3$ \\
& A1 & Água subterrânea & 1,0 \\
\hline P2 & S2 & Solo/sedimento & $0-0,3$ \\
& A2 & Água subterrânea & 1,5 \\
\hline P3 & S3 & Solo/sedimento & $0-0,8$ \\
& A3 & Água subterrânea & 0,8 \\
\hline P4 & S4 & Solo/sedimento & $0-1,0$ \\
& A4 & Água subterrânea & 1,0 \\
\hline Acesso p/ lagoa & S5 & Solo/sedimento & $0-0,6$ \\
\hline \multirow{2}{*}{ Canaleta de drenagem } & SD1 & Sedimento & 0 \\
& LP1 & Líquido percolado & 0 \\
\hline Rio Saboó & SD2 & Sedimento & 0 \\
\hline Estuário & E & Água do mar & 0,5 \\
\hline
\end{tabular}

Em função da origem desconhecida dos solos usados na cobertura dos resíduos do aterro e da influência pretérita das marés no aporte de sedimentos ao manguezal, utilizou-se neste trabalho o termo solo/sedimento para designar as amostras de solo.

Os pontos P1 e P3, apesar de estarem situados em locais com características remanescentes de manguezal, também se encontravam bastante antropizados, com presença de entulhos misturados ao solo.

A perfuração e instalação dos poços de monitoramento foram realizadas nos pontos $\mathrm{P} 3 \mathrm{e} \mathrm{P} 4$, conforme as Normas NBR 13895 e NBR 15495-1 da Associação Brasileira de Normas Técnicas - ABNT (1997, 2007) e CETESB (2001b). Os poços P1 e P2 já se encontravam instalados na área. As profundidades dos poços variaram de 0,80 a 1,80 m. Na tabela 1 são indicadas as profundidades de amostragem de água e intervalo de coleta do solo/sedimento. Cerca de 2,0 $\mathrm{kg}$ de amostra de solo/sedimento foram coletados em cada ponto. As amostras coletadas ao longo do perfil de solo P3 foram misturadas, por possuírem características semelhantes, compondo uma amostra composta. $\mathrm{O}$ mesmo foi efetuado com as amostras do perfil do ponto P4. No entorno da área de estudo não havia locais adequados para obtenção de amostras de referência.

Amostras de solo/sedimento foram coletadas sobre o aterro (S5) (Figura 2B), bem como materiais de aspecto lodoso misturado com sedimentos (SD1 e SD2), acumulados em canaletas de drenagem e próximos à lagoa de líquidos percolados do aterro (Figura 2C).

As amostras sólidas foram acondicionadas em sacos plásticos e refrigeradas a $4{ }^{\circ} \mathrm{C}$.

Amostras de líquido percolado do aterro foram obtidas em uma canaleta (LP1) (Figura 2D) e às margens da lagoa (LP2 e LP3). 

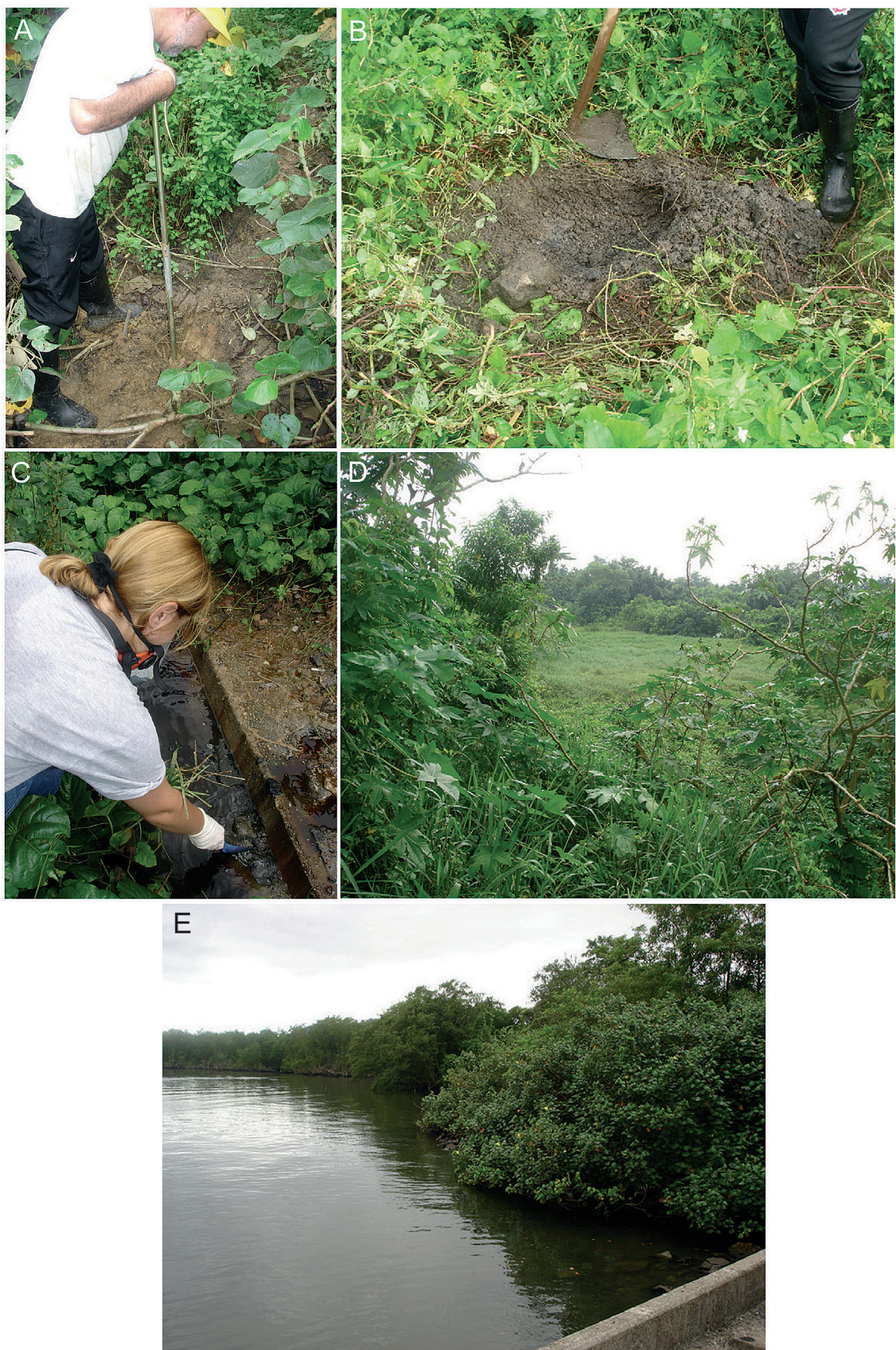

FIGURA 2 - (A) Perfuração de poço de monitoramento no ponto P3, (B) Material de cobertura do aterro: solo argiloso com entulho (S5), (C) Coleta de material lodoso com sedimento e líquido percolado do aterro em canaleta de drenagem (SD1, LP1), (D) Lagoa de líquido percolado do aterro, (E) Pier no limite norte da área, próximo ao ponto P3, com vista para o Canal de Piaçaguera e do mangue. 
A amostragem das águas subterrâneas dos poços de monitoramento foi feita com amostradores descartáveis do tipo bailer, após esgotar os poços 3 vezes. As técnicas de amostragem das águas superficiais do Rio Saboó (R), do estuário (E) (Figura 2E) e dos poços de monitoramento seguiram as normas da American Public Health Association (APHA 2005). Após a coleta foram determinados, in situ, os parâmetros temperatura, condutividade elétrica (CE), oxigênio dissolvido (OD) (Eletrodo P3-oxi/cond da WTW), pH e Eh (Eletrodo Multiline da WTW) e alcalinidade (HYPOLITO et al 2008). As amostras foram acondicionadas em frascos plásticos em três alíquotas: uma sem preservante e mantida a $4{ }^{\circ} \mathrm{C}$ e as outras com $\mathrm{HNO}_{3}$ (até $\mathrm{pH}<2$ ) e $\mathrm{H}_{2} \mathrm{SO}_{4}($ até $\mathrm{pH}<2$ ).

\subsection{Trabalhos laboratoriais}

\subsubsection{Tratamento das amostras e análises laboratoriais}

As amostras sólidas foram secas a temperatura ambiente. Em seguida, foram destorroadas, homogeneizadas, peneiradas para separação da fração menor que $2 \mathrm{~mm}$, quarteadas e pesadas.

Alíquotas da fração menor que $2 \mathrm{~mm}$ foram destinadas às análises granulométricas, mineralógicas, determinação de $\mathrm{pH}$, capacidade de troca catiônica (CTC) e extrações químicas de elementos maiores e traços.

As análises granulométricas foram realizadas pelo método da Pipeta de Robson (dispersão total) no Laboratório de Geoquímica (IGc/USP). A composição mineralógica dos solos foi determinada por difração de raios $\mathrm{X}$, com radiação $\mathrm{Cu} \mathrm{K \alpha}$ (equipamento SIMENS-D-5000), no Laboratório de DRX (IGc/USP).

As medidas de $\mathrm{pH}$ do solo foram realizadas na Escola Superior de Agricultura Luiz de Queirós (ESALQ/USP) pela medição potenciométrica da atividade hidrogeniônica do sobrenadante das misturas de solo/ $\mathrm{KCl}(1 \mathrm{~N})$ e solo/ $\mathrm{H}_{2} \mathrm{O}$ na proporção $1 \mathrm{~mL}: 2,5 \mathrm{~mL}$ (solo:solução). A partir dos resultados do $\mathrm{pH}$ determinou-se o $\Delta \mathrm{pH}$ (dada por $\left.\mathrm{pH}_{\mathrm{H} 2 \mathrm{O}}-\mathrm{pH}_{\mathrm{KCl}}\right)($ MEKARU \& UEHARA 1972, TAN 1982), que permite avaliar a carga predominante nos coloides do solo. Valores positivos indicam que os coloides estão carregados negativamente e os negativos, carregados positivamente; o valor nulo indica que se atingiu o ponto de carga zero (ZPC).

A CTC foi determinada no Laboratório de Fertilidade dos Solos (ESALQ/USP) e calculada pela soma dos cátions trocáveis $\left(\mathrm{K}^{+}, \mathrm{Ca}^{2+}, \mathrm{Mg}^{2+}\right)$ com a acidez potencial $\left(\mathrm{H}^{+}+\mathrm{Al}^{3+}\right)$. As bases foram determinadas a partir de extração dos teores dispo- níveis por resina trocadora; os cátions foram extraídos com solução de acetato de cálcio $(1 \mathrm{~N} \mathrm{a} \mathrm{pH}$ 7,0 ), titulada com solução de $\mathrm{NaOH} 0,025 \mathrm{~mol} \mathrm{~L}^{-1}$.

A composição química dos solos/sedimentos foi determinada por fluorescência de raios X (equipamento PW2400/Philips) no Laboratório de FRX (IGc/USP).

\subsubsection{Extrações com água e ácido nítrico $\left(\mathrm{HNO}_{3} 8 \mathrm{M}\right)$}

A entrada de substâncias antropogênicas nos sistemas solo-sedimento-água do ambiente altera as concentrações das espécies químicas dissolvidas ou adsorvidas às superfícies de partículas sólidas (solos/sedimentos). A fase solúvel do solo corresponde à fração de íons biodisponíveis e, por este motivo, é importante na avaliação ecotoxicológica. O acúmulo de íons metálicos adsorvidos às partículas sólidas do solo, portanto, pode representar um perigo aos organismos. Nesse sentido, extrações iônicas realizadas em solos/sedimentos permitem identificar e quantificar os tipos de metais pesados presentes nesses materiais.

Existem várias técnicas para extrair íons das frações solúveis e trocáveis do solo. Muitos autores utilizam a digestão em meio ácido fraca $\left(\mathrm{HNO}_{3} /\right.$ $\mathrm{H}_{2} \mathrm{O}_{2}$ ) (MORSCH 1991 apud ROBAINA et al. 2002) para determinar a fração fracamente ligada ou parcial às partículas do solo. Alguns métodos propõe ainda uma digestão mais branda com uso de solução de $\mathrm{HCl}$ 1:1 (NASCIMENTO 2003 apud SILVÉRIO et al. 2006, PEREIRA et al. 2007), ou até moderada, com água régia $\left(\mathrm{HCl}+\mathrm{HNO}_{3} \pm \mathrm{H}_{2} \mathrm{O}_{2}\right)$ (SILVÉRIO et al. 2006, PEREIRA et al. 2007). Outros métodos de extração com ácidos fortes, como por exemplo, com $\mathrm{HClO}_{4}+\mathrm{HF}+\mathrm{HNO}_{3}+\mathrm{HCl}$ (ROBAINA et al. 2002, USEPA 1996) foram propostos para digestão total de metais. Estes métodos têm por objetivo permitir estabelecer comparações dos valores obtidos nas extrações com aqueles de referência, como os VGQS (valores-guia de qualidade de sedimentos).

Para verificar a presença de metais pesados associados às fases solúvel e trocável do solo realizaram-se extrações com água destilada e com solução $\mathrm{HNO}_{3}(8 \mathrm{M})$, conforme métodos utilizados por MARQUES (2003) e HYPOLITO et al. (2009). As amostras de solo foram secas a $40{ }^{\circ} \mathrm{C}$ por $24 \mathrm{~h}$, antes de serem pesadas $(1,0000 \mathrm{~g})$ e transferidas em béqueres de $150 \mathrm{~mL}$, onde foram adicionados $50 \mathrm{~mL}$ de solução de extração (água destilada ou $\mathrm{HNO}_{3} 8 \mathrm{M}$ ). A mistura foi agitada a cada 30 minutos e, após $2 \mathrm{~h}$, filtrada. A solução filtrada foi analisada por espectrofotometria de absorção atômica (932B Plus/GBC). 


\subsubsection{Análise química das amostras de água}

As amostras líquidas foram analisadas por espectrofotometria de absorção atômica para determinação de cátions (932B Plus/GBC), fotometria de chama para determinação de $\mathrm{Na}^{+}$e $\mathrm{K}^{+}$(B262/ Micronal) e cromatografia líquida para determinação de ânions (ICS 90/Dionex). Todas as análises foram realizadas no Laboratório de Hidrogeoquímica III (CEPAS-IGc/USP).

\section{RESULTADOS E DISCUSSÕES}

\subsection{Solos}

Os resultados da análise granulométrica das amostras de solo indicam predomínio da fração areia (acima de 60\%) e frações argila e silte em torno de $7-15 \%$ e $15-25 \%$, respectivamente (Tabela 2). Pela projeção dos dados granulométricos dos solos em diagrama triangular (SHEPARD 1954), as amostras são classificadas texturalmente como areia síltica. Tais resultados corroboram os dados de literatura que indicam que os solos de manguezais do Estado de São Paulo são arenosos, com pouca argila e quantidade variável de silte (ROSSI \& MATTOS 2002).
A composição mineralógica da fração areia é constituída principalmente de quartzo; as frações silte e argila apresentam óxidos-hidróxidos de ferro amorfos, caulinita, illita e gibbsita.

A CTC varia de 40,31 a 86,0 mmol $\mathrm{kg}^{-1}$ (Tabela 3). Esses valores estão de acordo com os minerais identificados nesses solos e são considerados relativamente baixos em comparação aos argilominerais 2:1, como vermiculitas e esmectitas. A caulinita, por exemplo, apresenta em média CTC de10 $\mathrm{cmol}_{\mathrm{c}} \mathrm{kg}^{-1}$ (MONIZ 1975), enquanto as illitas em torno de $40 \mathrm{cmol}_{\mathrm{c}} \mathrm{kg}^{-1}$ (FANNING \& KERAMIDAS 1977).

Os teores de matéria orgânica variam de médio (15-45 $\left.\mathrm{g} \mathrm{kg}^{-1}\right)$ a alto $\left(>45 \mathrm{~g} \mathrm{~kg}^{-1}\right)$ (Tabela 3 ), segundo a classificação de COCHRANE et al. (1985).

Os valores de $\Delta \mathrm{pH}$ positivos são indicativos da presença dominante de cargas negativas nas partículas coloidais do solo/sedimento e, portanto, de estarem aptos a adsorverem cátions.

As composições químicas do solo/sedimento (S) e do material coletado nas canaletas de drenagem e próximo à lagoa (SD) apresentam quantidades consideráveis de ferro e alumínio (Tabela 4). Dentre os elementos-traço analisados, constatou-se

TABELA 2 - Dados granulométricos das amostras de solo.

\begin{tabular}{cccc}
\hline \multirow{2}{*}{ Amostras } & \multicolumn{3}{c}{ Fração (\%) } \\
\cline { 2 - 4 } & Argila & Silte & Areia \\
\hline S1 & 10,44 & 15,74 & 73,82 \\
S2 & 12,06 & 25,18 & 62,76 \\
S3 & 14,85 & 21,11 & 64,04 \\
S4 & 7,54 & 18,37 & 74,09 \\
S5 & 13,02 & 21,34 & 65,64 \\
\hline
\end{tabular}

TABELA 3 - Concentração de bases, CTC, teores de M.O. e pH das amostras de solo/sedimento.

\begin{tabular}{|c|c|c|c|c|c|c|c|c|c|}
\hline \multirow{2}{*}{ Amostra } & $K^{+}$ & $\mathrm{Ca}^{2+}$ & $\mathrm{Mg}^{2+}$ & $A l^{3+}$ & CTC & \multirow{2}{*}{$\begin{array}{l}\text { M.O. } \\
g k^{-1}\end{array}$} & \multirow{2}{*}{$p H_{H 2 O}$} & \multirow{2}{*}{$p H_{K C l}$} & \multirow{2}{*}{$\begin{array}{c}\Delta p H \\
\left(p H_{H 2 O}-p H_{K C O}\right)\end{array}$} \\
\hline & \multicolumn{5}{|c|}{$\mathrm{mmol}_{\mathrm{c}} \mathrm{kg}^{-1}$} & & & & \\
\hline S1 & 3,0 & 61,0 & 5,0 & 7,0 & 81,0 & 32 & 4,40 & 3,70 & $+0,70$ \\
\hline S2 & 6,2 & 43,0 & 26,0 & 0,0 & 89,2 & 17 & 7,10 & 6,00 & $+1,10$ \\
\hline S3 & 21,6 & 99,0 & 36,0 & 20,0 & 176,6 & 86 & 4,20 & 3,90 & $+0,30$ \\
\hline S4 & 3,9 & 160,0 & 44,0 & 0,0 & 208,0 & 20 & 7,50 & 7,30 & $+0,20$ \\
\hline S5 & 4,0 & 186,0 & 18,0 & 0,0 & 225,0 & 32 & 7,20 & 7,00 & $+0,20$ \\
\hline
\end{tabular}


teores consideráveis de metais pesados que ultrapassam, em sua maioria, os valores de referência (VR) e de prevenção (VP) estabelecidos pela CETESB (2005): $\mathrm{Pb}\left(\mathrm{VR}=17 \mathrm{mg} \mathrm{kg}^{-1}\right.$ e VP= $72 \mathrm{mg}$ $\left.\mathrm{kg}^{-1}\right), \mathrm{Cu}\left(\mathrm{VR}=35 \mathrm{mg} \mathrm{kg}^{-1}\right.$ e $\left.\mathrm{VP}=60 \mathrm{mg} \mathrm{kg}^{-1}\right), \mathrm{Ni}$ $\left(\mathrm{VR}=13 \mathrm{mg} \mathrm{kg}^{-1}\right.$ e $\left.\mathrm{VP}=30 \mathrm{mg} \mathrm{kg}^{-1}\right)$ e $\mathrm{Zn}(\mathrm{VR}=60$ $\mathrm{mg} \mathrm{kg}^{-1}$ e VP= $300 \mathrm{mg} \mathrm{kg}^{-1}$ ).

Verificou-se a presença de metais pesados $(\mathrm{Pb}, \mathrm{Cu}, \mathrm{Ni}, \mathrm{Zn})$ em todos os pontos analisados. Seus teores, no entanto, variam em cada amostra devido à heterogeneidade composicional dos resíduos. Dentre os pontos analisados, S3 e SD2 apresentam maiores concentrações de $\mathrm{Pb}, \mathrm{Cu}$ e $\mathrm{Zn}$.
As extrações de metais da fase solúvel do solo com água destilada indicaram elevadas concentrações de íons de metais pesados (exceto $\mathrm{Pb}^{2+}$ ), que podem ser mobilizados pelas águas pluviométricas (Tabela 5). Os resultados refletem a composição química dos solos apresentada na tabela 4 , com destaque para os elevados teores de $\mathrm{Cu}$, Ni e Zn nas amostras $\mathrm{S} 3$, S1 e S5.

As soluções obtidas nas extrações com ácido nítrico apresentaram, conforme já era esperado, concentrações bem maiores de íons de metais pesados lixiviados do solo (Tabela 6). Todos os solos apresentam teores extraídos de $\mathrm{Pb}^{2+}$ e $\mathrm{Ni}^{2+}$ acima dos valores de referência estabelecidos pela CE-

TABELA 4 - Resultados analíticos de elementos maiores e traço determinados por fluorescência de raios X em amostras de solo/sedimento e lodo.

\begin{tabular}{cccccccc}
\hline \multicolumn{3}{c}{ Solo/sedimento } & & & \multicolumn{2}{c}{ Sedimento-Lodo } \\
\hline $\begin{array}{c}\text { Elementos } \\
\text { maiores (\%) }\end{array}$ & $S 1$ & $S 2$ & $S 3$ & $S 4$ & $S 5$ & $S D 1$ & $S D 2$ \\
\hline $\mathrm{SiO}_{2}$ & 60,98 & 55,83 & 51,82 & 53,38 & 70,20 & 72,00 & 37,34 \\
$\mathrm{Al}_{2} \mathrm{O}_{3}$ & 11,89 & 15,05 & 7,84 & 19,07 & 10,45 & 9,54 & 15,71 \\
$\mathrm{MnO}$ & 0,05 & 0,28 & 0,06 & 0,08 & 0,19 & 0,09 & 0,19 \\
$\mathrm{MgO}$ & 0,86 & 1,65 & 0,78 & 2,04 & 0,90 & 1,26 & 1,52 \\
$\mathrm{CaO}$ & 2,25 & 2,17 & 1,90 & 1,22 & 1,90 & 2,55 & 4,04 \\
$\mathrm{Na}{ }_{2} \mathrm{O}$ & 1,38 & 1,02 & 0,64 & 0,99 & 1,57 & 1,59 & 0,64 \\
$\mathrm{~K}_{2} \mathrm{O}$ & 2,81 & 2,70 & 2,02 & 3,41 & 2,80 & 2,95 & 2,00 \\
$\mathrm{P}_{2} \mathrm{O}_{5}$ & 1,69 & 0,64 & 4,16 & 0,60 & 0,37 & 0,79 & 1,88 \\
$\mathrm{Fe}_{2} \mathrm{O}_{3}$ & 5,52 & 8,52 & 12,12 & 8,78 & 5,72 & 3,82 & 8,25 \\
\hline Elementos traço (mg kg & $-1)$ & & & & & & \\
\hline $\mathrm{Pb}^{2+}$ & 341 & 70 & 689 & 84 & 175 & 66 & 209 \\
$\mathrm{Cu}^{2+}$ & 59 & 16 & 910 & 67 & 40 & 75 & 693 \\
$\mathrm{Ni}^{2+}$ & 50 & 33 & 67 & 60 & 62 & 9 & 60 \\
$\mathrm{Zn}^{2+}$ & 112 & 138 & 683 & 215 & 267 & 90 & 1007 \\
\hline
\end{tabular}

TABELA 5 - Resultados analíticos de extrações de íons metálicos dos solos com água ( $\mathrm{mg} \mathrm{kg}^{-1}$ ).

\begin{tabular}{cccccccc}
\hline & \multicolumn{3}{c}{ Solo/sedimento } & & \multicolumn{3}{c}{ Sedimento-lodo } \\
\hline & $S 1$ & $S 2$ & $S 3$ & $S 4$ & $S 5$ & $S D 1$ & $S D 2$ \\
\hline $\mathrm{Pb}^{2+}$ & n.d & n.d. & n.d & n.d. & n.d. & 0,30 & 0,25 \\
$\mathrm{Cu}^{2+}$ & 4,85 & 1,98 & 2,88 & 4,96 & 2,88 & 0,52 & 2,79 \\
$\mathrm{Ni}^{2+}$ & 1,94 & n.d. & 44,93 & 23,92 & n.d. & 0,05 & 0,17 \\
$\mathrm{Zn}^{2+}$ & 5,82 & 1,98 & 108,82 & 27,78 & 5,76 & 1,99 & 2,60 \\
$\mathrm{Fe}(\mathrm{t})$ & 21,36 & 6,95 & n.d. & 14,39 & 14,39 & 16,38 & 27,30 \\
$\mathrm{Mn}$ & 6,79 & 30,76 & 80,87 & 9,59 & 9,59 & 0,99 & 1,06 \\
\hline n.d.: não detectado & & & & & & &
\end{tabular}


TESB (2005). Teores de $\mathrm{Cu}^{2+}$ apresentam-se elevados nas amostras S1, S3 e S4, enquanto os de $\mathrm{Zn}^{2+}$ superam os valores de referência nas amostras $\mathrm{S} 3$, S4, S5. A disponibilidade do ferro também é bastante elevada, assim como a do manganês.

\subsection{Líquido percolado}

Os líquidos percolados (LP) produzidos no aterro apresentam valores de $\mathrm{pH}$ variando de neutro a alcalino, Eh redutor e elevada condutividade elétrica. Assim como as amostras de material lodoso (SD), essas também apresentaram elevados teores de chumbo, enquanto outros íons não foram detectados (Tabela 7).

\section{3 Águas}

As amostras de água subterrânea apresentaram temperatura média de $33,80^{\circ} \mathrm{C}$ e $\mathrm{pH}$ próximo a 7,0 (Tabela 8). Os potenciais de óxido-redução dos pontos A1 e A4 são negativos, devido à influência da matéria orgânica associada ao manguezal. As amostras A2 e A3 apresentam valores positivos devido aos elevados valores de ferro, que podem estar sofrendo redução da forma $\mathrm{Fe}^{3+}$ para $\mathrm{Fe}^{2+}$.

A água do estuário (E) do Canal de Piaçaguera, com pH característico da água do mar, ao redor de 8,2, influencia as características do Rio Saboó (R), que apresenta valores de $\mathrm{pH}$ e condutividade elétrica elevados (Tabela 8). Estas águas podem ser classificadas como salinas, com salinidade igual ou superior a 30\%o (Resolução CONAMA 357/ 2005).

Os valores elevados de condutividade elétrica, assim como das concentrações de $\mathrm{Cl}^{-}, \mathrm{Na}^{+}$e $\mathrm{K}^{+}$ das amostras A1 e A3 (que distam menos de $50 \mathrm{~m}$ do estuário) indicam similaridade com a composi-

TABELA 6 - Resultados analíticos de extrações de íons metálicos dos solos com $\mathrm{HNO}_{3} 8 \mathrm{M}\left(\mathrm{mg} \mathrm{kg}^{-1}\right)$.

\begin{tabular}{cccccccc}
\hline \multicolumn{9}{c}{ Solo/sedimento } & \multicolumn{3}{c}{ Sedimento-lodo } \\
\hline Analito & $S 1$ & $S 2$ & $S 3$ & $S 4$ & $S 5$ & $S D 1$ & SD2 \\
\hline $\mathrm{Pb}^{2+}$ & 340,50 & 50,51 & 402,35 & 55,80 & 114,97 & 44,73 & 19,82 \\
$\mathrm{Cu}^{2+}$ & 46,79 & 12,89 & 828,67 & 64,77 & 25,63 & 32,51 & 19,89 \\
$\mathrm{Ni}^{2+}$ & 16,78 & 14,72 & 25,61 & 57,55 & 49,55 & 2,32 & 21,40 \\
$\mathrm{Zn}^{2+}$ & 38,83 & 34,71 & 650,90 & 107,62 & 109,02 & 40,52 & 24,78 \\
$\mathrm{Fe}(\mathrm{t})$ & 1350,46 & 3222,26 & 6728618,21 & 9688,09 & 13436,08 & 4359,97 & 991,37 \\
$\mathrm{Mn}{ }^{2+}$ & 105,54 & 107,11 & 352,46 & 739,41 & 2081,27 & 313,95 & 981,46 \\
\hline
\end{tabular}

Itálico: valores que ultrapassam os valores de prevenção estabelecidos por CETESB (2005).

TABELA 7 - Resultados analíticos das amostras do líquido percolado do aterro $\left(\mathrm{mg} \mathrm{dm}^{-3}\right)$.

\begin{tabular}{lcccc}
\hline Parâmetros & Limite de detecção & LP1 & LP2 & LP3 \\
\hline $\mathrm{pH}$ & & 7,67 & 7,10 & 7,95 \\
$\mathrm{Eh}(\mathrm{V})$ & & $-0,05$ & $-0,037$ & $-0,109$ \\
$\mathrm{CE}\left(\mu \mathrm{S} \mathrm{cm}^{-1}\right)$ & & 6220 & 10540 & 3620 \\
$\mathrm{Na}^{+}$ & 0,10 & 1204,66 & 6692,54 & 513,10 \\
$\mathrm{~K}^{+}$ & 0,10 & 251,10 & 1081,98 & 161,04 \\
$\mathrm{~Pb}^{2+}$ & 0,01 & 0,58 & 2,60 & 1,91 \\
$\mathrm{Cu}^{2+}$ & 0,002 & n.d. & n.d. & n.d. \\
$\mathrm{Ni}^{2+}$ & 0,002 & n.d. & n.d. & n.d. \\
$\mathrm{Zn}^{2+}$ & 0,005 & n.d. & n.d. & n.d. \\
\hline
\end{tabular}

n.d.: não detectado 
TABELA 8 - Resultados analíticos das águas subterrâneas e superficiais.

\begin{tabular}{|c|c|c|c|c|c|c|c|}
\hline \multirow{2}{*}{ Parâmetro } & \multirow{2}{*}{$\begin{array}{l}\text { Limite de } \\
\text { detecção }\end{array}$} & \multicolumn{4}{|c|}{ Subterrâneas } & \multicolumn{2}{|c|}{ Superficiais } \\
\hline & & $A 1$ & $A 2$ & $A 3$ & $A 4$ & $E$ & $R$ \\
\hline $\mathrm{pH}$ & & 6,83 & 6,97 & 6,47 & 6,72 & 8,30 & 7,47 \\
\hline $\mathrm{Eh}(\mathrm{V})$ & & $-0,09$ & $+0,04$ & $+0,13$ & $-0,07$ & $+0,13$ & $+0,17$ \\
\hline $\mathrm{CE}\left(\mu \mathrm{S} \mathrm{cm}^{-1}\right)$ & & 10230 & 14230 & 9730 & 2440 & 33000 & 27100 \\
\hline Força Iônica (mol L-1) & & 0,1637 & 0,2277 & 0,1557 & 0,0390 & 0,5280 & 0,4336 \\
\hline Alcalinidade $\left(\mathrm{CaCO}_{3}\right)$ & & 149,94 & 187,42 & 240,97 & 139,23 & & \\
\hline $\mathrm{Cl}^{-}\left(\mathrm{mg} \mathrm{dm}^{-3}\right)$ & 0,008 & 5442,50 & 577,70 & 6094,00 & 359,60 & 14252,00 & 9137,00 \\
\hline $\mathrm{Na}^{+}\left(\mathrm{mg} \mathrm{dm}{ }^{-3}\right)$ & 0,10 & 3007,80 & 341,30 & 3178,50 & 273,00 & 6826,20 & 5247,70 \\
\hline $\mathrm{K}^{+}\left(\mathrm{mg} \mathrm{dm}^{-3}\right)$ & 0,10 & 110,80 & 16,00 & 95,70 & 23,60 & 259,40 & 186,30 \\
\hline $\mathrm{Pb}^{2+}\left(\mathrm{mg} \mathrm{dm}^{-3}\right)$ & 0,01 & 2,71 & 1,97 & 2,44 & 0,51 & 2,19 & 2,44 \\
\hline $\mathrm{Zn}^{2+}\left(\mathrm{mg} \mathrm{dm}^{-3}\right)$ & 0,002 & 0,48 & 0,46 & 0,59 & 0,32 & 983,63 & 0,96 \\
\hline $\mathrm{Cu}^{2+}\left(\mathrm{mg} \mathrm{dm}^{-3}\right)$ & 0,002 & 0,07 & 0,09 & n.d. & n.d. & n.d. & 0,16 \\
\hline $\mathrm{Ni}^{2+}\left(\mathrm{mg} \mathrm{dm}^{-3}\right)$ & 0,005 & n.d. & n.d. & 0,22 & n.d. & 0,42 & 0,14 \\
\hline
\end{tabular}

A: poço de monitoramento, E: estuário, R: rio

ção da água do mar. Já as amostras A2 e A4, que distam, respectivamente, $800 \mathrm{~m}$ e $1000 \mathrm{~m}$ do mar, indicam influência muito menor da cunha salina na composição das águas subterrâneas.

As concentrações do íon $\mathrm{Pb}^{2+}$ nos poços ultrapassam 200 vezes os valores de potabilidade da Portaria $\mathrm{N}^{\circ}$ 2914/2011do Ministério da Saúde (0,01 mg $\left.\mathrm{dm}^{-3}\right)$. O Cu e o $\mathrm{Zn}$ também se encontram presentes nas águas subterrâneas, mas com valores abaixo daqueles de intervenção da CETESB $\left(2 \mathrm{mg} \mathrm{dm}^{-3}\right.$ e $5 \mathrm{mg}$ $\mathrm{dm}^{-3}$ respectivamente), enquanto o $\mathrm{Ni}\left(0,02 \mathrm{mg} \mathrm{dm}^{-3}\right)$ está acima destes valores apenas na amostra A3. As amostras $\mathrm{R}$ e $\mathrm{M}$ apresentam teores de $\mathrm{Pb}$ e $\mathrm{Zn}$ acima do valor permitido $\left(0,12 \mathrm{mg} \mathrm{dm}^{-3}\right)$ pela Resolução CONAMA 357 para águas salinas de Classe 2.

Ao se projetarem os dados de concentrações de $\mathrm{Pb}, \mathrm{Cu}$ e $\mathrm{Zn}$ em função do $\mathrm{pH}$ em gráficos de STUMM \& MORGAN (1995) e em diagramas de $\mathrm{pH}$ em função do potencial de óxido-redução (GARRELS et al. 1965, BROOKINS 1988, STUMM \& MORGAN 1995) constata-se que o chumbo pode se apresentar nas formas de $\mathrm{Pb}^{2+}$, $\mathrm{PbCO}_{3}$ (aq), $\mathrm{Pb}\left(\mathrm{CO}_{3}\right)_{2}{ }^{2-}$ e $\mathrm{PbSO}_{4}$ (aq) e o zinco nas formas $\mathrm{Zn}_{2}(\mathrm{OH})^{3+}, \mathrm{Zn}(\mathrm{OH})_{2}(\mathrm{aq}), \mathrm{ZnOH}^{+}$e $\mathrm{Zn}^{2+}$.

A presença dos íons metálicos $\mathrm{Pb}^{2+}, \mathrm{Zn}^{2+}$ e $\mathrm{Ni}^{2+}$ nas soluções deve-se a fenômenos de complexação e, especialmente, à força iônica (I) (Tabela 8). Os valores de I calculados para as amostras de água são bastante elevados, implicando na diminuição do coeficiente de atividade e, consequentemente, no aumento da solubilidade dos íons metálicos em solução, bem como aqueles associados ao solo/sedimento. A influência da água do mar no aumento da força iônica e na liberação de íons metálicos dos sedimentos em região de manguezal também foi constatada nos estudos de HYPOLITO et al (2005) e NASCIMENTO (2007).

A amostra A4 (poço P4), distante cerca de $200 \mathrm{~m}$ da área de estudo, seria adotada como referência. No entanto, os resultados analíticos indicaram a presença de contaminantes, devido ao tipo de uso e ocupação do solo no entorno da área de estudo, predominantemente industrial, e à circulação de veículos automotores de grande porte na avenida limítrofe à área.

\section{CONCLUSÕES}

A área de estudo encontra-se intensamente degradada pelo antigo aterro de resíduos portuários instalado sobre o manguezal. O descarte de resíduos de naturezas diversas, por anos, causou modificações na vegetação, no solo e nas águas.

Os resultados das análises químicas dos solos/ sedimentos indicaram teores consideráveis de metais pesados $(\mathrm{Pb}, \mathrm{Zn}, \mathrm{Cu}$ e $\mathrm{Ni})$, ultrapassando os valores de intervenção estabelecidos pela CETESB (2005).

Os teores variáveis de metais pesados em cada amostra provavelmente refletem a heterogeneidade composicional dos resíduos aterrados, bem como sua distribuição espacial na área.

Elevados teores de matéria orgânica, além de capacidade de troca catiônica moderada a elevada, conferem aos solos/sedimentos capacidade de adsor- 
verem os íons poluentes. Apesar desta capacidade de retenção de íons metálicos, testes realizados por extrações de metais das fases solúvel (em água) e adsorvida (em $\mathrm{HNO}_{3}$ ) do solo, indicaram a possibilidade desses íons serem lixiviados no ambiente (chuvas, variação do nível freático, entrada da cunha salina, formação e escoamento do líquido percolado etc.).

Os íons poluentes encontram-se presentes nas águas subterrâneas e superficiais (estuário e Rio Saboó) pode estar relacionado a fenômenos de complexação e ao elevado valor da força iônica. Embora as condições de $\mathrm{pH}$ e Eh favoreçam a ocorrência de íons $\mathrm{Pb}, \mathrm{Cu}$ e $\mathrm{Zn}$ nas suas formas sulfato e/ou carbonato, a água do mar pode exercer influência no aumento da força iônica e na liberação de íons metálicos dos solos para as águas.

\section{AGRADECIMENTOS}

Ao Centro de Pesquisas de Águas Subterrâneas - CEPAS do Instituto de Geociências - USP, pela infraestrutura laboratorial (Laboratórios de Hidrogeoquímica II e III).

\section{REFERÊNCIAS BIBLIOGRÁFICAS}

ABNT - ASSOCIAÇÃO BRASILEIRA DE NORMAS TÉCNICAS. 1997. NBR 13895: Construção de poços de monitoramento e amostragem. ABNT, Rio de Janeiro, 21 p.

ABNT - ASSOCIAÇÃO BRASILEIRA DE NORMAS TÉCNICAS. 2007. NBR 15495-1: Poços de monitoramento de águas subterrâneas em aquíferos granulados. Parte 1: Projeto e construção.. ABNT, Rio de Janeiro, 25 p.

APHA - AMERICAN PUBLIC HEALTH ASSOCIATION. 2005. Standard methods for the examination of water and wastewater. In: A.D. Eaton, L.S. Clesceri, E.W. Rice, A.E Greenberg (eds.) American Water Works Association. Washington, Water Pollution Control Federation, $21^{\text {st }}$ ed, $1368 \mathrm{p}$.

BERROCAL, R.A. 2009. Comportamento de íons de metais pesados $(\mathrm{Pb}$ e $\mathrm{Ni})$ e de compostos nitrogenados em área industrial impactada no Município de Cubatão - SP. Instituto de Geociências, Universidade de São Paulo, São Paulo, Dissertação de Mestrado, 110 p.

BROOKINS, D.G. 1988. Eh-pH diagrams for geochemistry. Springer, Berlin, $176 \mathrm{p}$.

CARMO, C.A.; ABESSA, D.M.S.; MACHADO NETO, J.G. 2011. Metais em águas, sedimentos e peixes coletados no Estuário de São Vicente-SP, Brasil. O Mundo da Saúde, 35(1): 64-70.

CETESB - COMPANHIA DE TECNOLOGIA DE SANEAMENTO AMBIENTAL. 1998. Mapeamento dos ecossistemas costeiros do Estado de São Paulo. C.C. Lamparelli, C.O. Moura (coords.). Ed. Páginas \& Letras, São Paulo, 108 p.

CETESB - COMPANHIA DE TECNOLOGIA DE SANEAMENTO AMBIENTAL. 2001a. Sistema Estuarino de Santos e São Vicente. Programa de Controle de Poluição - PROCOP/ Programa de Assistência Técnica. CETESB, São Paulo, 183 p.

CETESB - COMPANHIA DE TECNOLOGIA DE SANEAMENTO AMBIENTAL. 2001b. Manual de gerenciamento de áreas contaminadas. Projeto CETESB, GTZ. São Paulo, 389 p.

CETESB - COMPANHIA DE TECNOLOGIA DE SANEAMENTO AMBIENTAL. 2005. Valores Orientadores para Solos e Águas Subterrâneas do Estado de São Paulo. Decisão de Diretoria No 195-2005- E, de 23 de novembro de 2005.

COCHRANE, T.T.; SANCHEZ, L.G.; AZEVEDO, L.G.; PORRAS, J.A.; GARVE, C.L. 1985. Land in tropical America. CIAT-EMBRAPACPAC, 3 v.

DTA ENGENHARIA. 2003. Diagnóstico ambiental da área do Lixão da Alemoa. J.A.G. de O. Neto (coord.). Relatório Técnico, 63 p.

EMBRAPA - EMPRESA BRASILEIRA DE PESQUISA AGROPECUÁRIA. 1995. Procedimentos normativos de levantamentos pedológicos. Centro Nacional de Pesquisa de Solos, Brasília, $101 \mathrm{p}$.

FANNING, D.S.; KERAMIDAS, V.Z. 1977. Illite and glauconite. In: J.B. Dixon \& S.B. Weed (eds.) Minerals in Soil Environment. Madison, Wiscosin, Soil Sci. Soc Amer., p. 206-208.

FERREIRA, T.O. 2002. Solos de mangue do rio Crumahú (Guarujá - SP): pedologia e contaminação por esgoto doméstico. Escola Superior de Agricultura Luiz de Queiroz ESALQ, Universidade de São Paulo, Piracicaba, Dissertação de Mestrado, 113 p.

FERRER, L.M. 2001. Fixação e mobilidade de espécies de mercúrio no sistema sedimento/ água do mangue no Município de Cubatão, 
SP. Instituto de Geociências, Universidade de São Paulo, São Paulo, Dissertação de Mestrado, $122 \mathrm{p}$.

FIRME, M L.P. 2003. Caracterização físico-química de solos de mangue e avaliação de sua contaminação por esgoto doméstico via traçadores fecais. Escola Superior de Agricultura Luiz de Queiroz - ESALQ, Universidade de São Paulo, Piracicaba, Dissertação de Mestrado, $70 \mathrm{p}$.

GARRELS, R.M.; CHRIST, C.L. 1965. Solutions, Minerals and Equilibria. Harper \& Row Publishers, New York, $450 \mathrm{p}$.

GOMES, V.P.; AMARAL, C.; JÚNIOR, L.C.G.N.; CÉSAR, A.; ABESSA, D.M.S. 2009. Avaliação da contaminação por mercúrio nos sedimentos do Estuário de Santos -SP, Brasil. Revista Ceciliana, 1(2): 29-33.

GONÇALVES, W.F.O.; LUIZ-SILVA, W.; MACHADO, W.; NIZOLI, E.C.; SANTELLI, R.E. 2012. Geochemistry of intertidal sediment pore waters from the industrialized Santos-Cubatão Estuarine System, SE Brazil. Anais da Academia Brasileira de Ciências, 84(2): 427-441.

HYPOLITO, R., FERRER, L.M.; NASCIMENTO, S.C. 2005. Comportamento de espécies de mercúrio no sistema sedimento-água do mangue no Município de Cubatão, São Paulo. Águas Subterrâneas, 19(1):15-24.

HYPOLITO, R.; ANDRADE, S.; MARQUES, J.F., NASCIMENTO, S.C.; EZAKI, S. 2008. Alcalinidade - Metodologia para determinação em campo. Analytica, 35: 52-61.

HYPOLITO, R.; ANDRADE, S.; EZAKI, S.; MARQUES, J.F., NASCIMENTO, S.C.; 2009. Alcalinidade - Metodologia para determinação: método para amostragem e detecção de íons em águas da zona não saturada. Analytica, 38: 85-92.

HORTELLANI, M.A.; ABESSA, D.M.; SOUSA, E.C.P.M. 2008. Avaliação da contaminação por elementos metálicos dos sedimentos do Estuário Santos - São Vicente. Química Nova, 31(1): 10-19.

IPT - INSTITUTO DE PESQUISAS TECNOLÓGICA. 1998. Unidades de conservação ambiental e áreas correlatas no Estado de São
Paulo. São Paulo. Divisão de Minas e Geologia Aplicada, v.1.

MARQUES, J.F. 2003. Comportamento de íons $\mathrm{Pb}, \mathrm{Zn}$ e $\mathrm{Cu}$ em área impactada por escória, produto da reciclagem de baterias chumboácido. Instituto de Geociências, Universidade de São Paulo, São Paulo, Dissertação de Mestrado, $120 \mathrm{p}$.

MASSAD, F. 1999. Baixada Santista: implicações da história geológica no projeto de fundações. Solos e Rochas: Revista Latino Americana de Geotecnia, 22(1): 3-49.

MEKARU, T.; UEHARA, G. 1972. Anion adsorption in ferruginous tropical soils. Soil Science Society of America Proceedings, 36: 296-300.

MONIZ, A.C. 1975. Elementos de Pedologia. Livros Técnicos e Científicos Ed. S.A., Rio de Janeiro, $158 \mathrm{p}$.

NASCIMENTO, S.C. 2007. Comportamento de íons e sua associação a resíduos de indústria siderúrgica em manguezal do Sistema Estuarino de Santos-Cubatão/SP. Instituto de Geociências, Universidade de São Paulo, São Paulo, Tese de Doutorado, 112 p.

PEREIRA, J.C.; GUIMARÃES-SILVA, A.K.; NALINI JÚNIOR, H.A.; PACHECO-SILVA, E.; LENA, J.C. 2007. Distribuição, fracionamento e mobilidade de elementos traço em sedimentos superficiais. Química Nova, 30(5): 1249-1255.

PRADA-GAMERO, R.M. 2001. Mineralogia, físico-química e classificação dos solos de mangue do Rio Iriri no Canal de Bertioga (Santos, SP). Escola Superior de Agricultura Luiz de Queiroz, Universidade de São Paulo, Piracicaba, Dissertação de Mestrado, 78 p.

ROBAINA, L.E.; FORMOSO, M.L.L.; PIRES, C.A. DA F. 2002. Metais pesados nos sedimentos de corrente, como indicadores de risco ambiental - Vale do Rio Sinos, RS. Revista do Instituto Geológico, 23(2): 35-47.

ROSS, J.L.S.; MOROZ, I.C. 1997. Mapa Geomorfológico do Estado de São Paulo. Escala 1 : 500.000. Laboratório de Geologia Aplicada/ IPT-FAPESP, Mapas e Relatório.

ROSSI, M.; MATOS, I.F.A. 2002. Solos de mangue do Estado de São Paulo: caracterização química e física. Revista do Departamento de Geografia, 15: 101-113. 
SCHAEFFER-NOVELLI, Y. 1991. Manguezais Brasileiros: texto que sistematiza criticamente parte da produção científica. Instituto Oceanográfico, Universidade de São Paulo, São Paulo, Tese de Livre Docência, 2 v.

SHEPARD, F.P. 1954. Nomenclature based on sand-silt-clay ratios. Journal of Sedimentary Petrology, 24: 51-80.

SILVA, P.S.C. 2004. Caracterização química e radiológica dos sedimentos do Estuário de Santos, São Vicente e Baía de Santos. Instituto de Pesquisas Energéticas e Nucleares - IPEN, Universidade de São Paulo, São Paulo, Tese de Doutorado, $268 \mathrm{p}$.

SILVÉRIO, P.F.; NASCIMENTO, M.R.L.; MOZETO, A.A.A. 2006. Valores-Guia de Qualidade de Sedimentos de Ambientes Aquáticos Continentais e Valores de Referência de Metais e Metalóides em Sedimentos. In: A.A Mozeto, G.A. Umbuzeiro, W.F. Jardim (eds.) Métodos de coleta, análises físico-químicas e ensaios biológicos e ecotoxicológicos de sedimentos de água doce. São Carlos, Cubo Multimídia, p.71-89.

SIMÕES, E.C. 2007. Diagnóstico ambiental em manguezais dos complexos estuarinos da Baixada Santista e Cananéia no tocante a metais e compostos organoclorados. Instituto de Química, Universidade de São Paulo, São Carlos, Dissertação de Mestrado, 161 p.

SIQUEIRA, G.W.; LIMA, W.N.; MENDES, A.S.; APRILE, F.M.; BRAGA, E.S; MAHIQUES, M.M. 2004. Evolução do impacto ambiental causado por matéria orgânica, mercúrio e arsênio nos sedimentos de fundo do Sistema Estuarino de Santos. Geochimica Brasiliensis, 18(1): 54-63.

STUMM, W.; MORGAN, J.J. 1995. Aquatic chemistry, Chemical equilibria and Rates in Natural Waters. John Wiley \& Sons, New York, $3^{\text {rd }}$ ed., $1022 \mathrm{p}$.

TAN, K.H. 1982. Principles of Soil Chemistry. (Books in soils and the environment). Marcel Dekker, New York, 267 p.

USEPA - UNITED STATES ENVIRONMENTAL PROTECTION AGENCY. 1996. Method 3050B. Acid digestion of sediments, sludges and soils. Revision 2. December 1996, 12 p.

VIRGA, R.H.P. 2006. Análise quantitativa de metais pesados $(\mathrm{Cd}, \mathrm{Cr}, \mathrm{Cu}, \mathrm{Pb}$ e $\mathrm{Zn})$ em siris-azuis do gênero Callinectes sp (Crustacea, portunidae), provenientes do Rio Cubatão, Cubatão, São Paulo, Brasil. Universidade Católica de Santos, Santos, Dissertação de Mestrado, 105 p.

\section{Endereço dos autores:}

Janaína Mara Fortunato, Raphael Hypolito, Claudia Lucia de Moura, Silvia Cremonez Nascimento - Instituto de Geociências, Universidade de São Paulo, Rua do Lago, 562, Cidade Universitária, CEP: 05508080, Butantã, São Paulo, SP. E-mails: janaina_fortunato@hotmail.com, rhypo@igc.usp.br, clau_clau@ uol.com.br, scremo@usp.br 